\title{
Pengembangan Kriteria BUMN berbasis Balanced Scorecard
}

\author{
Dwi Pangesti Piorita, Arman Hakim Nasution, dan Aang Kunaifi \\ Departemen Manajemen Bisnis, Fakultas Bisnis dan Manajemen Teknologi, Institut Teknologi Sepuluh \\ Nopember (ITS) \\ e-mail: armanhakim.nasution@gmail.com
}

\begin{abstract}
Abstrak-Kementerian BUMN pada tahun 2012 telah bertekad untuk mengembangkan Kinerja Unggul dalam kerangka manajemen kinerja BUMN. Kinerja Unggul tersebut dinamakan KPKU, diadopsi dan diadaptasi dari Malcolm Baldrige Criteria for Performance Excellence yang telah terbukti sebagai sistem pengelolaan kinerja perusahaan paling komprehensif. Penelitian dilakukan pada salah satu perusahaan BUMN sektor industri strategis sub sektor heavy industry yang belum menerapkan KPKU dalam pengelolaan perusahaan. Penelitian ini bertujuan mengembangkan KPKU BUMN dengan basis BSC eksisting pada PT X. Penelitian ini dilakukan secara studi kasus dengan metode wawancara semi terstruktur. Hasil dari penelitian ini adalah daftar KPI korporat sesuai pedoman KPKU.
\end{abstract}

Kata Kunci-Balanced Scorecard, Cascading, Kriteria Penilaian Kinerja Unggul.

\section{PENDAHULUAN}

$\mathrm{S}$ TRUKTUR perekonomian suatu negara diperkuat dengan menempatkan sektor industri sebagai motor penggerak [1]. Indonesia berada pada kelompok negara semi industri dengan kontribusi sektor industri terhadap Produk Domestik Bruto mencapai 22\% [2]. Peningkatan kualitas industri dipengaruhi oleh peningkatan kualitas Sumber Daya Manusia nya, yang dapat dilihat dari peningkatan kinerja perusahaan. Untuk membuat sebuah tolok ukur yang sama, maka pada tahun 2012 Kementerian BUMN telah menetapkan Kriteria Penilaian Kinerja Unggul sebagai pedoman pengelolaan dan peningkatan kinerja BUMN. Ujung dari penilaian KPKU adalah untuk menentukan langkah bagaimana perusahaan agar memiliki daya saing yang tinggi, sebagai bentuk evaluasi perusahaan dan cara menilai kekuatan internal [3]. Penelitian ini bertujuan mengembangkan KPKU dengan basis BSC eksisting pada PT X untuk mencapai kinerja perusahaan yang ekselen.

\section{TINJAUAN PUSTAKA}

\section{A. Heavy Industry}

Heavy industry atau industri berat adalah industri yang di dalam kegiatannya menggunakan mesin-mesin berat, mengelola bahan mentah dalam jumlah yang sangat banyak dan memproduksi barang-barang dalam kategori yang tahan lama dan berat [4]. Industri berat merupakan sektor industri strategis dalam Kementerian BUMN. Bidang industri yang dianggap strategis antara lain 1) industri transportasi laut, udara, dan darat, 2) industri energi, 3) industri enjiniring/rekayasa dan desain, 4) industri mesin dan peralatan pertanian, 5) industri pertahanan, dan 6) industri pekerjaan umum/teknik sipil.

\section{B. Penilaian Kinerja}

Kinerja perusahaan harus dituangkan dalam sebuah kerangka penilaian kinerja yang memuat segala aktivitas dalam rantai nilai perusahaan untuk kemudian dapat digunakan sebagai umpan balik berupa informasi bagi perusahaan terkait prestasi capaian strategi perusahaan dan poin perbaikan yang harus direncanakan untuk perkembangan perusahaan di masa mendatang [5].

\section{Balanced Scorecard}

Balanced Scorecard merupakan konsep pengukuran kinerja bisnis yang terdiri dari serangkaian kegiatan penilaian implementasi strategi perusahaan yang memberikan pandangan (kerangka kerja terpadu) kepada manajer puncak untuk dapat melihat kondisi terkini perusahaan secara cepat dan komprehensif. Terdapat empat perspektif dalam BSC yaitu perspektif keuangan, perspektif pelanggan, perspektif proses bisnis internal, dan perspektif pembelajaran dan pertumbuhan. Balanced Scorecard terdiri dari dua kata yaitu balanced yang berarti berimbang dan scorecard yang berarti kartu skor, sehingga Balanced Scorecard dapat disebut pula dengan istilah kartu skor berimbang. Kartu skor digunakan untuk mencatat hasil kinerja seseorang, sedangkan kata berimbang dipilih untuk menunjukkan bahwa kinerja seseorang diukur secara berimbang dari dua aspek: keuangan dan non keuangan, jangka pendek dan jangka panjang, internal dan eksternal (Mulyadi) [6].

\section{Kriteria Penilaian Kinerja Unggul}

Kriteria Penilaian Kinerja Unggul (KPKU) BUMN merupakan pedoman pengukuran kinerja dan pengelolaan BUMN yang diadopsi dan diadaptasi dari Malcolm Baldrige Criteria for Performance Excellence. KPKU merupakan sejumlah pertanyaan tentang berbagai aspek fundamental pengelolaan organisasi dalam konteks pencapaian kinerja unggul, terdiri dari tujuh kategori yaitu 1) Kepemimpinan (leadership), 2) Perencanaan Strategis (strategic planning), 3) Fokus pada Pelanggan (customer focused), 4) Pengukuran, Analisis, dan Pengelolaan Pengetahuan (measurement, analysis, and knowledge management), 5) Fokus pada Tenaga Kerja (workforce focused), 6) Fokus pada Operasi (operation focused), 7) Hasil (result). KPKU memiliki delapan kelas kinerja dengan rentang skor 0-1000, yaitu 1) World Class Leader (rentang skor 876 - 1000), 2) Benchmark Leader (rentang skor 776 - 875), 3) Industry Leader (rentang skor 676 - 775), 4) Emerging Industry Leader (rentang skor 576 - 675), 5) Good-Performance (rentang skor 476 - 575), 6) Early Employment (rentang skor 376 - 475), 7) Early Result (rentang skor 276 - 375), 8) Early Development (rentang skor 0 - 275). 
Tabel 1.

BSC Eksisting PT X

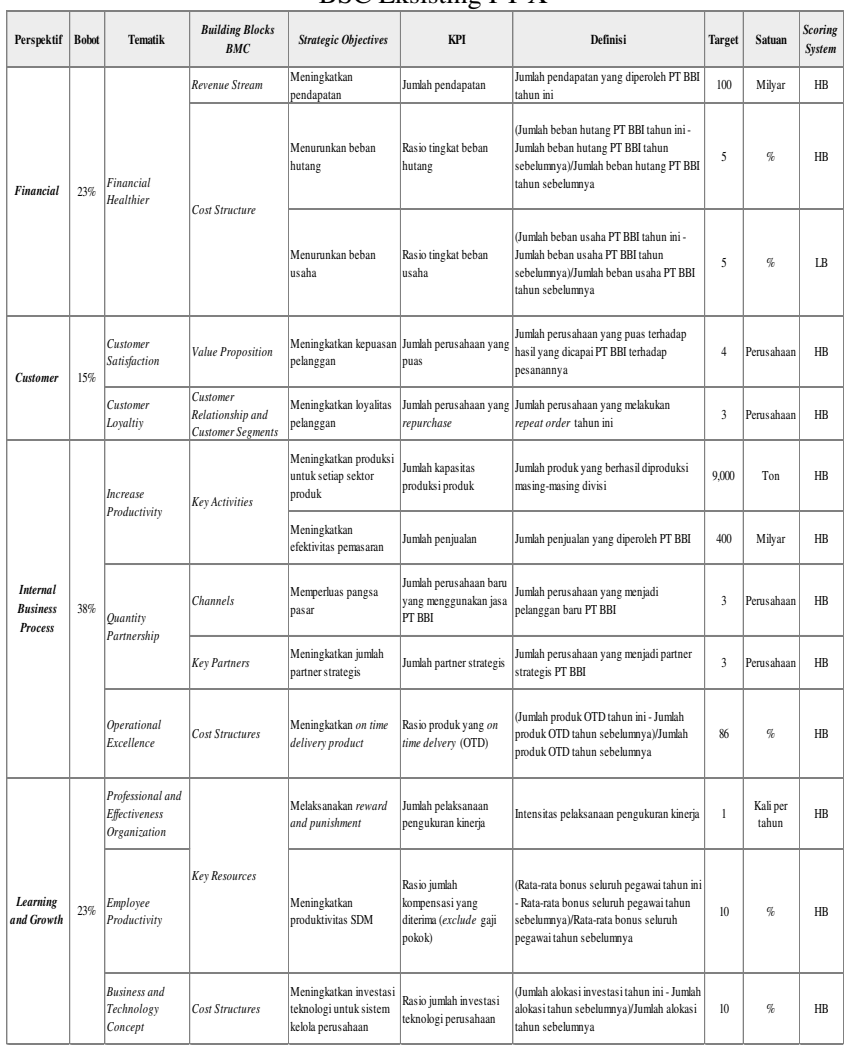

Tabel 2.

Penyelarasan Nilai BSC dan Baldrige

\begin{tabular}{ll}
\hline Kategori Hasil Baldrige & Perspektif Balanced Scorecard \\
\hline Hasil Fokus Pelanggan & Pelanggan \\
Hasil Produk dan Layanan & $\begin{array}{l}\text { Nilai Produk dan Nilai Layanan Pelanggan } \\
\text { (bagian dari Pelanggan) }\end{array}$ \\
Hasil Keuangan dan Pasar & Keuangan \\
Hasil Sumber Daya Manusia & Pembelajaran dan Pertumbuhan \\
Hasil Efektivitas Organisasi & Proses Bisnis Internal \\
Hasil Tata Kelola dan Tanggung & $\begin{array}{l}\text { Tidak secara khusus diteliti namun mungkin } \\
\text { merupakan bagian dari hasil proses bisnis internal }\end{array}$ \\
\hline
\end{tabular}

\section{E. Key Performance Indicator}

Menurut Banerjee dan Buoti [7], Key Performance Indicator merupakan ukuran berskala dan kuantitatif yang digunakan untuk mengevaluasi kinerja organisasi dalam tujuan mencapai target organisasi. KPI juga digunakan untuk menentukan objek yang terukur, melihat tren, dan mendukung pengambilan keputusan. Dalam menyusun KPI harus mempertimbangkan SMART goal [8]. SMART merupakan singkatan dari lima prinsip dalam penetapan tujuan, yaitu 1) Specific, 2) Measurable, 3) Achievable, 4) Relevant, 5) Time-based.

\section{METODOLOGI PENELITIAN}

\section{A. Metode dan Tahapan Penelitian}

Penelitian ini dilakukan secara studi kasus pada PT X. Terdapat tiga tahapan dalam penelitian ini. Tahap yang pertama adalah identifikasi potensi penelitian. Tahap yang kedua adalah penyelarasan perspektif BSC dan kategori KPKU. Tahap yang ketiga adalah perumusan KPI Korporat berdasarkan KPKU BUMN.

\section{B. Lokasi dan Waktu Penelitian}

Penelitian ini berlangsung di PT X yang beralamat di Jalan K.H.M Mansyur No. 229 Surabaya, 60162. Penelitian

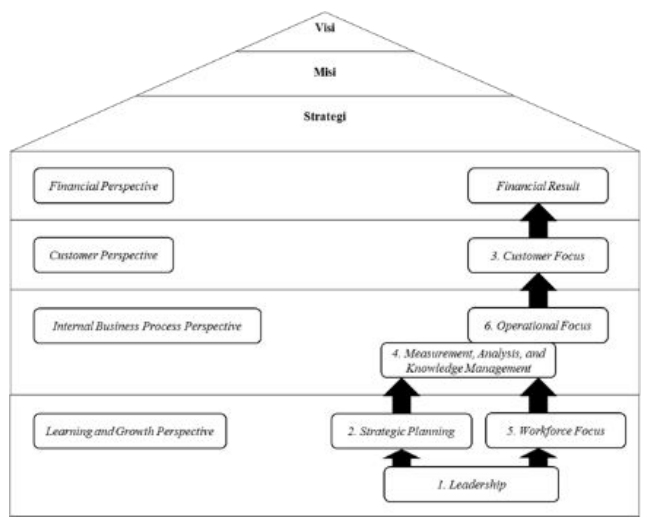

Gambar 1. Kerangka Pemetaan Perspektif BSC ke dalam Kategori KPKU BUMN.

Tabel 3 .

Matriks Identifikasi Strategic Objectives (1)

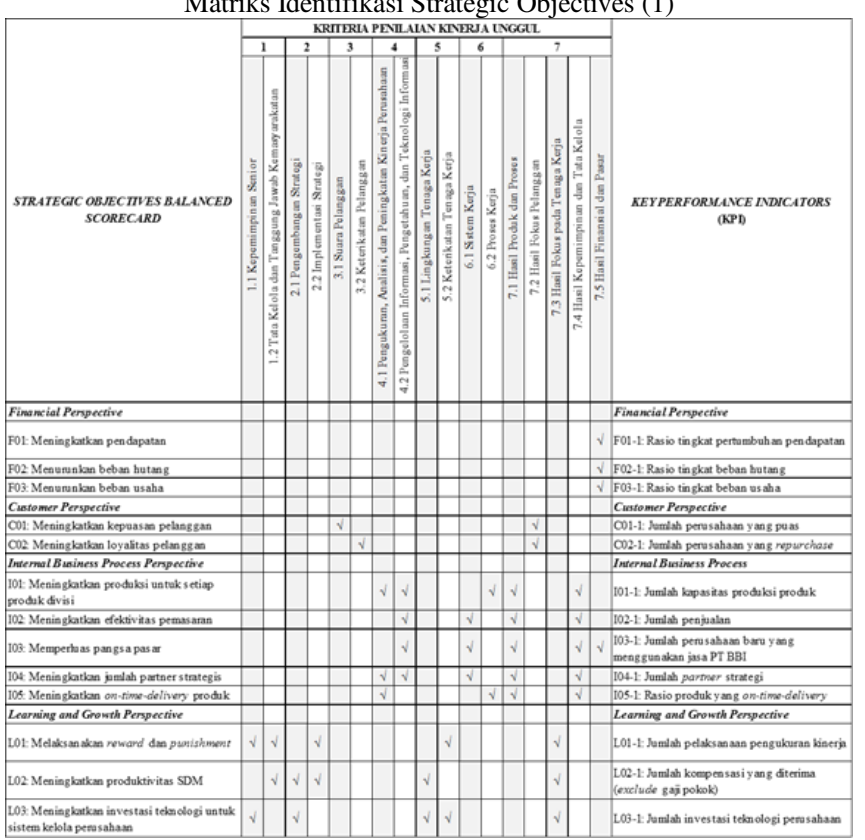

ini dilakukan dalam serangkaian program magang kerja sama PT X dengan ITS dengan waktu penelitian berlangsung dari bulan September hingga November 2017.

\section{Desain Penelitian}

Desain penelitian merupakan kerangka kerja dari pelaksanaan penelitian yang berisi rincian prosedur yang penting untuk memperoleh informasi yang dibutuhkan untuk menyusun dan/atau memecahkan masalah penelitian [9]. Desain penelitian akan membantu peneliti menentukan rincian-rincian aspek praktis dalam memecahkan permasalahan penelitian. Jenis penelitian yang dilaksanakan adalah penelitian eksploratif, yaitu jenis rancangan penelitian yang bertujuan untuk mendapatkan wawasan dan pemahaman terhadap situasi masalah yang dihadapi peneliti. Penelitian ini menggunakan pendekatan kualitatif dan kuantitatif (campuran).

\section{Jenis Data dan Teknik Pengumpulan Data}

Penelitian ini menggunakan data primer dan data sekunder. Data primer diperoleh melalui wawancara semiterstruktur, yaitu serangkaian kegiatan wawancara yang terdiri dari beberapa pertanyaan utama yang diajukan kepada responden dan juga memungkinkan adanya pertanyaan tambahan apabila dibutuhkan [10]. Data sekunder diperoleh dari data internal perusahaan dan kajian 
pustaka terhadap beberapa ketentuan Kementerian BUMN terkait KPKU.

Tabel 4.

Matriks Identifikasi Strategic Objectives (2)

\begin{tabular}{|c|c|c|c|}
\hline Strategic Objectives BSC & Bobot & Sub Kategori KPKU & Bobot \\
\hline \multirow{5}{*}{ Meningkatkan pendapatan } & \multirow{5}{*}{$8 \%$} & Hasil produk dan proses & $35 \%$ \\
\hline & & Hasil fokus pelanggan & $15 \%$ \\
\hline & & Hasil fokus tenaga kerja & $10 \%$ \\
\hline & & Hasil kepemimpinan dan tata kelola & $25 \%$ \\
\hline & & Hasil finansial dan pasar & $15 \%$ \\
\hline Menurunkan beban hutang & $8 \%$ & Hasil kepemimpinan dan tata kelola & $100 \%$ \\
\hline \multirow{3}{*}{ Menurunkan beban usaha } & \multirow{3}{*}{$7 \%$} & Hasil produk dan proses & $50 \%$ \\
\hline & & Hasil fokus pelanggan & $15 \%$ \\
\hline & & Hasil fokus tenaga kerja & $35 \%$ \\
\hline \multirow{3}{*}{$\begin{array}{c}\text { Meningkatkan kepuasan } \\
\text { pelanggan }\end{array}$} & \multirow{3}{*}{$8 \%$} & Hasil produk dan proses & $65 \%$ \\
\hline & & Hasil fokus pelanggan & $25 \%$ \\
\hline & & Hasil finansial dan pasar & $10 \%$ \\
\hline \multirow{3}{*}{$\begin{array}{c}\text { Meningkatkan loyalitas } \\
\text { pelanggan }\end{array}$} & \multirow{3}{*}{$8 \%$} & Hasil produk dan proses & $50 \%$ \\
\hline & & Hasil fokus pelanggan & $35 \%$ \\
\hline & & Hasil finansial dan pasar & $15 \%$ \\
\hline \multirow{4}{*}{$\begin{array}{l}\text { Meningkatkan produksi untuk } \\
\text { setiap sektor produk }\end{array}$} & \multirow{4}{*}{$8 \%$} & Hasil produk dan proses & $50 \%$ \\
\hline & & Hasil fokus pelanggan & $25 \%$ \\
\hline & & Hasil fokus tenaga kerja & $15 \%$ \\
\hline & & Hasil finansial dan pasar & $10 \%$ \\
\hline \multirow{2}{*}{$\begin{array}{c}\text { Meningkatkan efektivitas } \\
\text { pemasaran }\end{array}$} & \multirow{2}{*}{$7 \%$} & Hasil produk dan proses & $50 \%$ \\
\hline & & Hasil finansial dan pasar & $50 \%$ \\
\hline \multirow{2}{*}{ Memperluas pangsa pasar } & \multirow{2}{*}{$7 \%$} & Hasil produk dan proses & $50 \%$ \\
\hline & & Hasil finansial dan pasar & $50 \%$ \\
\hline \multirow{5}{*}{$\begin{array}{c}\text { Meningkatkan jumlah partner } \\
\text { strategis }\end{array}$} & \multirow{5}{*}{$8 \%$} & Hasil produk dan proses & $25 \%$ \\
\hline & & Hasil fokus pelanggan & $10 \%$ \\
\hline & & Hasil fokus tenaga kerja & $10 \%$ \\
\hline & & Hasil kepemimpinan dan tata kelola & $45 \%$ \\
\hline & & Hasil finansial dan pasar & $10 \%$ \\
\hline \multirow{3}{*}{$\begin{array}{l}\text { Meningkatkan on-time- } \\
\text { delivery product }\end{array}$} & \multirow{3}{*}{$8 \%$} & Hasil produk dan proses & $55 \%$ \\
\hline & & Hasil fokus pelanggan & $35 \%$ \\
\hline & & Hasil fokus tenaga kerja & $10 \%$ \\
\hline $\begin{array}{c}\text { Melaksanakan reward dan } \\
\text { punishment }\end{array}$ & $7 \%$ & Hasil fokus tenaga kerja & $100 \%$ \\
\hline \multirow{2}{*}{$\begin{array}{c}\text { Meningkatkan produktivitas } \\
\text { SDM } \\
\end{array}$} & \multirow{2}{*}{$8 \%$} & Hasil produk dan proses & $50 \%$ \\
\hline & & Hasil fokus tenaga kerja & $50 \%$ \\
\hline \multirow{3}{*}{$\begin{array}{c}\text { Meningkatkan invetasi } \\
\text { teknologi untuk sistem kelola } \\
\text { perusahaan }\end{array}$} & \multirow{3}{*}{$8 \%$} & Hasil produk dan proses & $45 \%$ \\
\hline & & Hasil fokus tenaga kerja & $15 \%$ \\
\hline & & Hasil kepemimpinan dan tata kelola & $40 \%$ \\
\hline
\end{tabular}

\section{E. Teknik Sampling}

Sampel dalam penelitian ini merupakan SDM perusahaan dalam tataran middle to top level management. Teknik pengambilan sampel yang digunakan dalam penelitian ini adalah purposive sampling, dimana proses penentuan sampel didasarkan atas pertimbangan khusus.

\section{F. Teknik Pengolahan Data}

Terdapat dua kali wawancara dalam penelitian ini. Wawancara pertama digunakan untuk memetakan perspektif BSC ke dalam kategori KPKU dan menghasilkan matriks identifikasi strategic objective. Wawancara kedua digunakan untuk menentukan target spesifik PT X. Target spesifik terpilih akan digunakan untuk merumuskan KPI korporat.

\section{HASIL DAN DISKUSI}

\section{A. Balanced Scorecard Eksisting PT BBI}

Bagian ini menampilkan empat perspektif BSC eksisting PT X yang dapat dilihat pada Tabel 1.

\section{B. Penyelarasan Perspektif BSC dan Kategori KPKU}

Terdapat teori yang menjelaskan mengenai penyelarasan nilai-nilai pada perspektif BSC dengan kategori Malcolm
Tabel 5.

Daftar KPI PT X Tahun 2018

\begin{tabular}{|c|c|c|c|}
\hline No & Indikator & Satuan & Target \\
\hline I & Keuangan dan Pasar & & \\
\hline 1 & Revenues growth and number of commercial product & $\%$ & $147 \%$ \\
\hline 2 & EBITDA Margin & $\%$ & $100 \%$ \\
\hline 3 & Turnover Periode & Hari & 26.12 \\
\hline II & Fokus Pelanggan & & \\
\hline 4 & Customer Loyalty & $\%$ & $70 \%$ \\
\hline 5 & Enable On-Time Product Delivery & $\%$ & $80 \%$ \\
\hline III & Efektivitas Produk dan Proses & & \\
\hline 6 & Increasing order / contract booked & $\%$ & $146 \%$ \\
\hline 7 & TKDN product $(\mathrm{AoD})$ & $\%$ & $85 \%$ \\
\hline 8 & Efficient Supply Chain Cost \& Operation & $\%$ & $2 \%$ \\
\hline 9 & Order Fulfillment Rate & $\%$ & $71 \%$ \\
\hline 10 & Plant Capacity Utilization Rate & $\%$ & $80 \%$ \\
\hline IV & Fokus Tenaga Kerja & & \\
\hline 11 & Peningkatan Kompetensi Pegawai & $\%$ & $100 \%$ \\
\hline 12 & Tenaga Kerja Lokal untuk Proyek di Daerah & $\%$ & $90 \%$ \\
\hline $\mathbf{v}$ & $\begin{array}{l}\text { Kepemimpinan, Tata Kelola, dan Tanggung Jawab } \\
\text { Kemasyarakatan }\end{array}$ & & \\
\hline 13 & Kinerja PKBL (Program Kemitraan dan Bina Lingkungan) & & \\
\hline & a. Efektivitas Penyaluran & $\%$ & $80 \%$ \\
\hline & b. Kolektibilitas Penyaluran Pinjaman & $\%$ & $80 \%$ \\
\hline 14 & Index GCG & Skor & 70 \\
\hline 15 & Portal BUMN Compliance & $\%$ & $100 \%$ \\
\hline 16 & Sinergi BUMN (AoD) & & \\
\hline & a. Transaksional & $\%$ & $70 \%$ \\
\hline & b. Kolaborasi & $\%$ & $100 \%$ \\
\hline
\end{tabular}

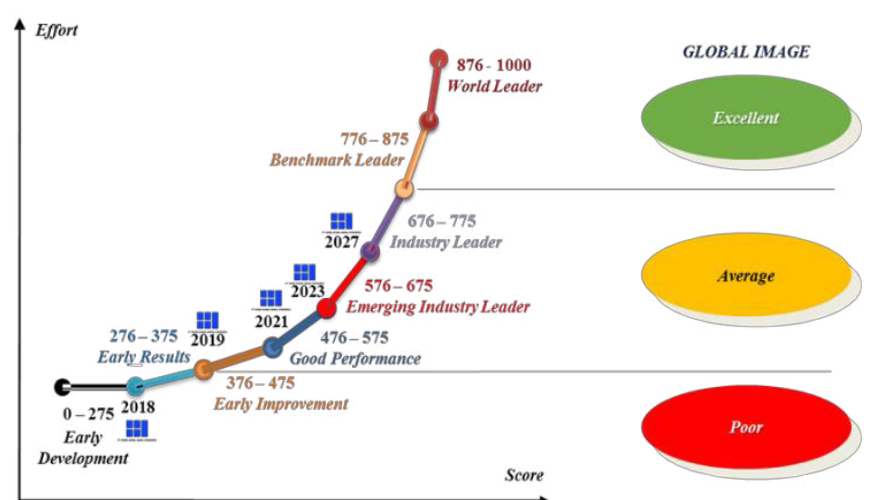

Gambar 2. Roadmap Pengembangan KPKU BUMN pada PT X

Baldrige yang digunakan sebagai acuan peneliti dalam merumuskan KPKU BUMN pada PT X [11]. Konsep penyelarasan nilai BSC dan Baldrige dapat dilihat pada Tabel 2. Berdasarkan konsep tersebut maka dapat dibuat kerangka pemikiran seperti pada Gambar 1. Selanjutnya dibuat sebuah matriks untuk memetakan tiga belas strategic objectives BSC eksisting ke dalam kategori KPKU, seperti pada Tabel 3 dan Tabel 4.

\section{Perumusan KPI Korporat berdasarkan KPKU BUMN}

Terdapat lima tahapan dalam perumusan KPI korporat, antara lain: 1) Identifikasi KPI, 2) Penentuan KPI terpilih, 3) Pembobotan KPI terpilih, 4) Penentuan target per KPI terpilih, 5) Pengesahan kontrak manajemen. Untuk memudahkan perhitungan capaian KPI maka dibuat Kamus Indikator dan Formulir Isian KPI. Identifikasi KPI dilakukan dengan cara memetakan sumber identifikasi KPI perusahaan yang terdiri dari visi dan misi, sasaran strategi, strategi, critical success factor, dan KPI perusahaan ke dalam kategori KPKU yang terdiri dari keuangan dan pasar, fokus pelanggan, efektivitas produk dan proses, fokus tenaga kerja, serta kepemimpinan, tata kelola, dan tanggung jawab kemasyarakatan. Pembobotan KPI terpilih harus menyesuaikan dengan tingkat pertumbuhan perusahaan. PT $\mathrm{X}$ mencapai tingkat pertumbuhan perusahaan sebesar $7 \%$, 
maka dari itu proporsi bobot yang harus diterapkan secara urut adalah sebagai berikut: kategori keuangan dan pasar sebesar 24\%, kategori fokus pelanggan sebesar $22 \%$, kategori efektivitas produk dan proses sebesar $20 \%$, kategori fokus tenaga kerja sebesar $10 \%$ serta kategori kepemimpinan, tata kelola, dan tanggung jawab kemasyarakatan sebesar $17 \%$. Dengan catatan bahwa pengalokasian bobot dilakukan sesuai ketentuan: 1) Selisih bobot antara satu KPI dengan KPI lainnya dalam satu perspektif yang sama, tidak boleh lebih dari $20 \%$ (balancing principles), dan 2) Jumlah nilai bobot seluruh KPI pada suatu perspektif sama dengan nilai bobot perspektif tersebut. Penentuan target didahului dengan melakukan evaluasi terhadap realisasi target tahun sebelumnya. Target dibuat dalam dua macam, yaitu target tahunan dan target triwulanan. Kontrak manajemen PT X yang berisi KPI Korporat telah disahkan dalam Rapat Umum Pemegang Saham tanggal 15 Desember 2017 di Jakarta. Daftar KPI PT $\mathrm{X}$ tahun 2018 dapat dilihat pada Tabel 5.

\section{Implikasi Manajerial}

Berdasarkan hasil penelitian telah dirumuskan KPI korporat sesuai dengan pedoman KPKU BUMN beserta bobot dan target. Hasil penelitian ini diharapkan dapat membawa PT X meraih skor pencapaian KPKU pada kelas kinerja Early Development dengan skor batas bawah 276. Untuk memudahkan proses pengembangan KPKU di masa mendatang pada PT X, maka peneliti juga telah membuat roadmap pengembangan KPKU yang dapat diterapkan oleh PT X seperti yang terdapat pada gambar 2 .

\section{KESIMPULAN}

Pengembangan KPKU BUMN dilakukan dengan menggunakan basis BSC eksisting PT X. Langkah pertama adalah membuat penyelarasan konsep antara strategic objectives pada BSC menuju kategori proses dan kategori hasil pada KPKU BUMN. Langkah kedua adalah perumusan KPI Korporat berdasarkan pedoman KPI dan KPKU BUMN dengan lima tahap yaitu identifikasi KPI, penentuan KPI terpilih, pembobotan KPI terpilih, penentuan target per KPI terpilih, dan pengesahan kontrak manajemen.

\section{DAFTAR PUSTAKA}

[1] Presiden Republik Indonesia, "Undang-Undang Republik Indonesia. Nomor: 17 Tahun 2007. Rencana Pembangunan Jangka Panjang Nasional.," 2007.

[2] A. Hartarto, "Indonesia Sudah Masuk Negara Industri. Industri Bisnis," 2017.

[3] Kementerian BUMN, "Surat Sekretaris Kementerian BUMN Nomor: S-08/S.MBU/2013. Penyampaian Pedoman Penentuan KPI dan KPKU BUMN," 2012.

[4] I. Abdurachmat and E. Maryani, "Geografi Ekonomi," Bandung, 1997.

[5] R. S. Kaplan and D. Norton, The Balanced Scorecard: Translating Strategy Into Action. Boston: Harvard Business School Press, 1996.

[6] Mulyadi, "Balanced Scorecard: Alat Manajemen Kontemporer Untuk Pelipatgandaan Kinerja Keuangan Perusahaan. Edisi Pertama. Persoalan di Indonesia," in Usahawan, Tahun XXVI, No 01, 2001.

[7] J. Banerjee and C. Buoti, "General Specifications of KPIs International Telecomunnication Union," 2012.

[8] G. Doran, "There's a S.M.A.R.T. Way to Write Management's Goals and Objectives," Manage. Rev., vol. 70, pp. 35-36, 1981.

[9] N. Malhotra, Riset Pemasaran: Pendekatan Terapan edisi Bahasa Indonesia. PT Indeks, 2009.

[10] M. Saunders, P. Lewis, and A. Thornhill, Research Methods for Bussiness Students, 4th ed. Harlow: Prentice Hal, Inc, 2007.

[11] M. Blazey, Insights to Performance Excellence 2006: An Inside Look at the 20016 Baldrige Award Criteria. American Society for Quality (ASQ) Press, 2006. 